\title{
Labour Market Programmes and the Equity-Efficiency Trade-off
}

Filges, Trine; Kennes, John; Larsen, Birthe; Tranæs, Torben

Document Version

Final published version

Publication date:

2005

License

CC BY-NC-ND

Citation for published version (APA):

Filges, T., Kennes, J., Larsen, B., \& Tranæs, T. (2005). Labour Market Programmes and the Equity-Efficiency Trade-off. Copenhagen Business School, CBS. Working Paper / Department of Economics. Copenhagen Business School No. 11-2005

Link to publication in CBS Research Portal

\section{General rights}

Copyright and moral rights for the publications made accessible in the public portal are retained by the authors and/or other copyright owners and it is a condition of accessing publications that users recognise and abide by the legal requirements associated with these rights.

\section{Take down policy}

If you believe that this document breaches copyright please contact us (research.lib@cbs.dk) providing details, and we will remove access to the work immediately and investigate your claim. 


\section{Copenhagen}

Business School

HANDELSHØJSKOLEN

\section{Department of Economies}

Copenhagen Business School

Working paper 11-2005

\section{LABOUR MARKET PROGRAMMES AND THE EQUITY-EFFICIENCY TRADE-OFF}

Trine Filges John Kennes Birthe Larsen Torben Tranas 


\title{
Labour Market Programmes and the Equity-Efficiency Trade-off *
}

\author{
Trine Filges, John Kennes, Birthe Larsen and Torben Tranæs ${ }^{\dagger}$
}

First Version: July 2003

This version: April 2005

\begin{abstract}
This paper studies labour market policy in a society where differently gifted individuals can invest in training to further increase their labour market productivity and where the government seeks both effiency and equity. Frictions in the matching process create unemployment and differently skilled workers face different unemployment risks. We show that in such an environment, training programmes that are targeted to the unemployed complement passive transfers (UI benefits), unlike a general training subsidy. Combining passive subsidies with a training subsidy conditioned on the individual being unemployed (for a while) - the typical Active Labour Market Programme - implies a favorable trade-off between equity and efficiency which encourages high spending on training.
\end{abstract}

${ }^{*}$ We wish to thank seminar participants at the CESifo 2003, employment and social insurance area conference for their comments on an earlier version of the present paper. We also wish to thank participants at the Mortensen Conference, Sandbjerg, 2004 and at a CAM seminar, University of Copenhagen.

${ }^{\dagger}$ 1. Socialforskningsinstituttet, email: tif@sfi.dk, 2. University of Copenhagen, email: john.kennes@econ.ku.dk,3. Copenhagen Business School, email: bl.eco@cbs.dk, 4. Rockwool Foundation, email: tt@rff.dk 


\section{Introduction}

A stylized fact is about to emerge among the developed countries. Passive and active unemployment programmes seem to be complementary tools to the governments. Passive programmes are traditional unemployment insurance schemes and active programmes are training activities targeted at unemployed individuals as opposed to, for instance, a general training or education subsidy. Active programmes can be education aiming at upgrading the unemployed workers' skills or employment programmes supposed to prevent skill loses during periods of unemployment.

Figure 1 illustrates the patterns by which public funds are spent on passive and active policy programmes among selected OECD countries. Active and Passive policy seem to be complements. The apparent complementary pattern is also found following a particular country over time. In this case major reforms are visible as structural shifts. In fact, it is hard to find examples of countries to whom the picture suggests that the two policy measures are substitutes rather than complements (see the Appendix).

Another feature that has emerged together with the higher emphasis placed on active policy by many advanced countries since the mid $1990 \mathrm{~s}^{1}$, is that the high spenders among these seem to operate on a more favorable equity-efficiency trade off than the other countries. We see this by comparing Figure 1 to Figure 2, which suggests the equity-efficiency trade-off for the

\footnotetext{
${ }^{1}$ See the European Commision (2004) and OECD (2003).
} 


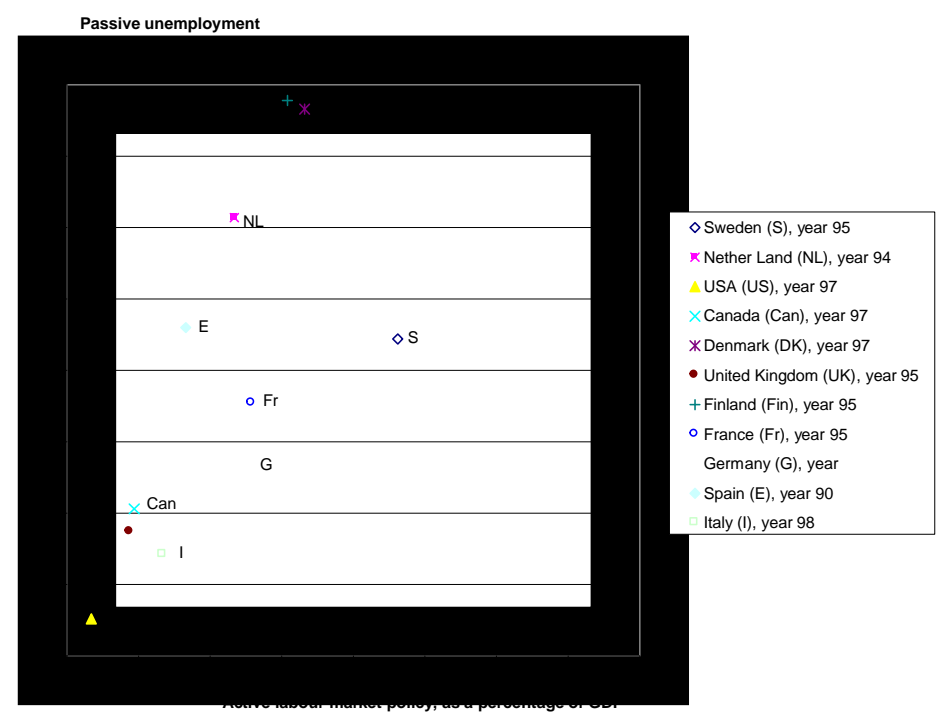

Figure 1: Active and passive labour market policy as percentages of GDP for OECD countries

group of countries considered. Consider for example the three countries which spend relatively most on Active and Passive Labour market policy, Finland, Denmark and Sweden. Those countries are also the countries with the lowest gini-coefficients and still is GDP per capita not significantly lower than for the other OECD countries. On the other hand, the USA, the UK, and Italy are spending relatively little on labour market policy and are also the countries with the most unfavorable trade-off between GDP and equality. France and the Nether Lands are in between the two groups; Canada is doing better and Germany and Spain worse in terms of equity given their spending on labor market policy.

Suppose that the optimal policy for any given weight placed on equity 
relative to efficiency, reveals complementarity, then the reason for the phenomenon in Figure 2 could be that as long as active and passive policy measures are used in the optimal proportions (and that the active programmes are efficiently organized) then higher spending creates not only higher equity but also a more favorable trade-off between equity and efficiency in the sense that the equality goals are not as expensive to reach as they would otherwise have been. That is, spending on programmes in an optimal way moves you to the right in Figure 2.

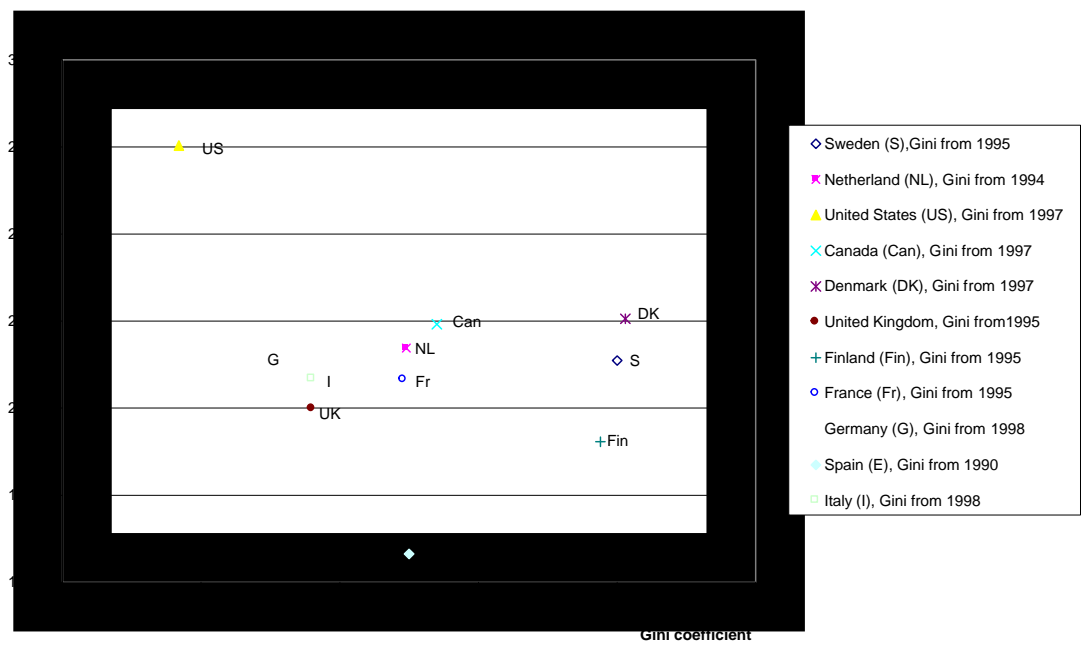

Figure 2: Ginicoefficient and GDP per capita for OECD countries

In this paper we discuss what features could potentially account for this phenomenon. We consider an economy with two types of working-life paths; one in the "fast lane" and one doing unskilled jobs. The unskilled jobs are simple jobs, they require little in terms of ability and skills and the 
productivity is low independently of the workers abilities. The advanced jobs on the other hand require skills, and the productivity and wage can be high. However, the content of the skills required changes frequently and in order to continue to be able to perform well in an advanced job your skills have to be adjusted accordingly. Hence, a worker who wants to keep an advanced job has to re-invest continuously in training in order to maintain a constant productivity distance to unskilled labour. That is the life in the "fast lane". These assumptions are inspired by the way new technology often influences the work situation. ${ }^{2}$

In order to focus the policy discussion we assume that all education opportunities which yield a positive private return have been undertaken, and on top of that we consider a labour market that allocates labour efficiently. But the labour market produces significant wage dispersion if workers are heterogeneous in ability; the disadvantaged workers receive much lower wages and face higher unemployment risk than advantages workers. Therefore, policy is justified if the government is also concerned with equity.

\footnotetext{
${ }^{2}$ New technology changes fast and the complementary skills acquired in order to manage any given technology decade change fast as a consequence. In such an environment, human capital investment is an ongoing concern; re-investments in learning is a necessity in many jobs; also in lower level skilled jobs. In order to keep a job as a computer operator one has to train continuously. If you are only able to operate old versions of soft-ware and equipment even though these are just a few years old, this is almost like you have no professional computer skills at all, which implies that you work as unskilled labour as far as computer jobs are concerned. Staying a head in a good job requires training continuously. So training costs are not something that are incurred once and for all and then you are skilled for the rest of your life. Of course, this problem is of no concern to individuals that abstain altogether from investing in training.
} 
The government in this paper has taste for both efficiency and equity and in order to pursue its concerns it considers two policy instruments. UI benefits and training subsidies, either a general education subsidy that all workers can take-up a while or a more targeted one that only some workers can take-up, long term unemployed workers, for instance. These instruments have different effects on the labour market. Unemployment falls if workers are better educated or trained and increases if workers obtain higher unemployment benefits. However, higher benefits reduce inequality. UI benefits are automatically given disproportionately to low income individuals as they are unemployed the most, and hence, a UI benefit scheme is a way of rewording low income individuals without distorting much the incentives for human capital investments at the top. Also an education or training subsidy can only reduce inequality if not all workers take it up, which does not happen automatically. All this is developed in a model of competitive labour auctions with coordination frictions (Julien, Kennes and King 2000, Shimer 2001).

The focus of our policy analysis is the following questions: are active programs complements to passive programs, and if so what is the best active complement to a passive UI benefit scheme, an education subsidy scheme for all or a training subsidy targeted at the least able workers. These questions, in particular the one concerning general versus targeted policy, have not been addressed by the fast advancing literature on how to organize unem- 
ployment policy (targeted policy in our terminology). ${ }^{3}$ And in contrast to the economics of education literature we focus on a governments (possibly) equity concerns as that drives the policy conclusion. For instance, there are no externalities in our model to make training subsidies optimal from an efficiency point of view. But there could be an equity motivated case for a training subsidy in situations where the advantaged workers face little unemployment and the disadvantaged workers face high unemployment. The advantaged workers invest in training and their expected private return covers the costs of the investment. They all choose the "fast lane" strategy. The disadvantaged individuals might also find it worth the while to train if it had not been for the risk of unemployment and the associated reoccurring idleness of costly skills. If the expected unemployment is high then the private return - the higher wage during the employment spells - is not high enough to cover the training costs incurred. So a subsidy might be called for here. However, as mentioned above, a training subsidy taken up by all is never optimal because it will not improve on equity. A training subsidy can be optimal only if it is possible to restrict it to the disadvantaged individuals. But as we shall see, there is a limited scope for using self-selection schemes unless mimicking can be made expensive; for instance, by conditioning the

\footnotetext{
${ }^{3}$ This literatur is surveyed in Frederiksen and Holmlund (2003). One of the more complex contributions of this litteratur, to follow along from the seminal paper by Shavell and Weiss (1979), is the recent study by Pavoni and Violante (2004) who characterizes the optimal sequense of different elements of labour market policies along an unemployment spell. Their main conclusion is that the timing of the variours elements - passive as well as active - of a targeted policy is very important for the effectiveness of the overall policy.
} 
subsidy on worker characteristics - directly or indirectly.

This is where active labour market policy comes in. Ability is private information so the conditioning needs to be indirectly and these programmes are indirectly targeted to the disadvantaged workers: participation is conditioned on a certain duration of unemployment prior to programme participation, and disadvantaged workers are the ones most likely to experience long term unemployment.

The optimal combination of UI benefits and targeted training subsidies (i) greatly reduces the equity-efficiency trade-off, (ii) increases the complementarity relationship between optimal active and passive policies and increases the use of both for given preferences. The reduction in the equityefficiency trade-off cannot be achieved by a passive subsidy that is only given to the long term unemployed. The reason why a targeted active subsidy works better than a targeted passive subsidy is that a disadvantaged worker's earning capacity goes up and so does realized earnings when he or she is being subsidized into training. A passive subsidy does not increase the worker's earnings capacity.

The paper is organized as follows. In section 2, we introduce a simple directed search model with a government that wish to maximize a social welfare function using a number of policy instruments. In section 3, we solve the equilibrium of the model with general training, whereas Section 4 is concerned with the equilibrium when training is targeted. In section 5, we evaluate the model numerically. Section 6 is a discussion and in Section 
7 we offer some concluding remarks.

\section{The model}

The workforce consists of a total population of $N$ infinitely lived workers. The workers are risk neutral with a subjective rate of time preference equal to $\beta$. There are two types of workers, $i \in\{A, D\}$ where type $A$ are advantaged and type $D$ are disadvantaged. A fraction $\eta$ of the labour force is advantaged and the remaining fraction is disadvantaged.

Workers can choose to train, $h=1$, or not, $h=0$. For a worker of type $i$, let $y_{h}^{i}$ denote the productivity during employment where $y_{1}^{i}>y_{0}^{i}$. Let the cost of training be $c_{i}-g$ units of output per period, where $g$ is a government subsidy to training. The training decision is modelled as a decision to pursue a career that requires a constant investment in skills (as in any balanced growth path). Therefore, higher productivity is achieved only if the worker pays this cost each period regardless of employment status.

Search and coordination friction. It is associated with frictions to get workers and jobs coordinated. Firms have free entry and open job vacancies with a resource cost $k$ per vacancy. The job vacancies are directed towards specific types of labour, search is directed, and each group of workers, distinguished by type and training investment, are in distinct submarkets with independently determined quantities of vacancies. Matching in each submarket is random. Therefore, if $v$ job vacancies are opened, a job searcher 
in this submarket is approached by a firm with probability

$$
p=1-e^{-\phi}
$$

where $\phi=v / s$ is the ratio of $v$ vacancies to $s$ job searchers in the submarket. We assume that all job matches are destroyed with a common exogenous probability, $\delta$.

Wage determination. Let $\Lambda$ denote the present value of a match between a worker of human capital level $h$ and a job vacancy. This present value is given by

$$
\Lambda=\frac{y-(c-g) h+\beta \delta(V+\Pi)}{1-\beta(1-\delta)}
$$

where $V$ is the present value of a job searcher and $\Pi$ is the expected profit of an unmatched job. Wages are determined by a simple labour auction market (ref: Julien, Kennes and King 2000) ${ }^{4}$. Thus the present value $V$ of a job searcher is given by

$$
V=\max \{V(u)+\lambda(\phi)(\Lambda-V(u)), 0\}
$$

where $\lambda(\phi) \equiv 1-e^{-\phi}-\phi e^{-\phi}$ is the probability the worker has multiple offers and $V(u)$ is the value of an unemployed worker. The value $V$ is the 'reserve wage' of each labour auction. The equilibrium present value of a job vacancy is given by

$$
\Pi=\max \left\{-k+e^{-\phi}(\Lambda-V(u)), 0\right\},
$$

\footnotetext{
${ }^{4}$ Specifically, the auction implies that the entire surplus of a match goes to the firm if the worker is matched with only one firm, and the entire surplus goes to the worker if (s)he is matched with two or more firms. An unmatched agent gets zero.
} 
where the free entry of job vacancies ensures that $\Pi=0$. A worker that leaves employment by a dislocation shock is a job searcher next period. The value of such a worker is given by

$$
V(u)=\max \{a-(c-g) h+\beta V, 0\},
$$

where $a$ denotes unemployment insurance benefits.

All workers can choose to either train or not. The worker's choice of human capital maximizes the return to a worker that enters the workforce unemployed. Thus

$$
h=\left\{\begin{array}{ll}
1 & \left.V\right|_{h=1} \geq\left. V\right|_{h=0} \\
0 & \text { otherwise }
\end{array} .\right.
$$

The values $\left.V\right|_{h=1}$ and $\left.V\right|_{h=0}$ are each determined by equation (6) for the appropriate value of $h$.

The government's problem. Let $W_{A}$ and $W_{D}$ denote the average per period income of advantaged and disadvantaged workers, respectively. Social welfare is determined by a social welfare function, which takes as its arguments, $W_{A}, W_{D}$ and $\eta$. It is convenient to assume that this social welfare function has the following functional form:

$$
Y=\gamma\left(\eta W_{A}+(1-\eta) W_{D}\right)+(1-\gamma) \min \left\{W_{A}, W_{D}\right\}, 0 \leq \gamma \leq 1,
$$

which is a weighted average of a Benthamite sum of utilities social welfare function and a Rawlsian social welfare function.

The government chooses transfers to unemployed and employed workers 
to maximize social welfare. In addition to the training subsidy, $g$, the government gives all unemployed workers an unemployment insurance benefit, $a$. The unemployment insurance is a passive benefit, because the worker has complete freedom on how it is spent. However, a general training subsidy is an active measure in a sense, because it has to be used on a specific activity, namely human capital investment. Both transfers are paid by a lump sum tax, $t$. The government balances its budget by setting

$$
t=\eta\left(a u_{A}+h g\right)+(1-\eta)\left(a u_{D}+h^{\prime} g\right),
$$

where $u_{A}$ and $u_{D}$ indicate the unemployment rates of advantaged and disadvantaged workers and $h$ and $h^{\prime}$ are their respective human capital choices.

\subsection{Equilibrium}

We can now derive the equilibrium of the model. First we derive the unemployment rate. Consider the gross labour market flows for a group of workers that have market tightness given by $\phi$. The fraction of workers employed in a period is given by

$$
q_{t}=z_{t}+p(\phi) s_{t}
$$

where $z_{t}$ is the fraction of all workers that are employed because they did not lose their jobs last period and $p(\phi) s_{t}$ is the fraction of all workers that are employed because of a successful job search this period. At the end of each period each worker becomes unemployed with probability $\delta$. Thus

$$
z_{t}=(1-\delta) q_{t-1}
$$


The flows in and out of employment imply that the steady state fraction $s$ workers engaged in job search in each period is given by

$$
s=\frac{\delta}{\delta+(1-\delta) p\left(\phi_{i}\right)}
$$

Job searchers that do not find a job are unemployed. Thus the unemployment rate is given by

$$
u=(1-p) s
$$

Jobs and human capital: the per period income of a worker investing in human capital can be written as follows

$$
W_{h}^{i}=G_{h}^{i}-h\left(c_{i}-g\right)-t, \quad i \in\{A, D\}, h \in\{0,1\},
$$

where $G_{h}^{i}$ is the worker's labour market income as a function of their training decision, $g$ is the government's subsidy to training, $h\left(c_{i}-g\right)$ is the cost of training that is born by the worker.

For each type of worker, $i \in\{A, D\}$, the training decision is determined by the difference between the cost of training, $c_{i}-g$, and the benefit of training, $G_{1}^{i}-G_{0}^{i}$. Thus the optimal value of $h$ for each group of workers is given by

$$
h=\left\{\begin{array}{ll}
1 & G_{1}^{i}-G_{0}^{i} \geq c_{i}-g . \\
0 & \text { otherwise }
\end{array} .\right.
$$

Given that a competitive search equilibrium model matches jobs and labour constrained efficiently, the equilibrium is simple to derive if we assume that the discount factor approaches unity (see Appendix 2). In particular, for each type of worker, equilibrium market tightness, $\phi_{h}^{i} \equiv v_{h}^{i} / s_{h}^{i}$, 
is that which maximizes steady state output net of recruiting costs. Thus the workers' labour market income is given by

$$
G_{h}^{i}=\max _{\phi}\left\{y_{h}^{i}\left(1-u_{h}^{i}\right)+a u_{h}^{i}-k v_{h}^{i}\right\}, i=A, D,
$$

where $u_{h}^{i}=e^{-\phi_{h}^{i}} s_{h}^{i}$ and $s_{h}^{i}=\delta /\left(\delta+(1-\delta)\left(1-e^{-\phi_{h}^{i}}\right)\right)$. Firms earn zero profits. Thus all income net of the cost of vacancies goes to workers. In competitive search equilibrium, this income is maximized and the solution is

$$
k=\frac{y_{h}^{i}-a}{1-(1-\delta)\left(1-\lambda\left(\phi_{h}^{i *}\right)\right)} e^{-\phi_{h}^{i *}},
$$

where $\lambda(\phi) \equiv 1-e^{-\phi_{h}^{i}}-\phi e^{-\phi_{h}^{i}}$ is the probability a job searcher gets multiple job offers and where $\phi_{h}^{i *}$ is the value of $\phi_{h}^{i}$ that maximizes (15). Hence

Proposition 1 There exists a unique $\phi_{h}^{i *}$ for each $y_{h}^{i}$.

Proof. $\phi_{h}^{i *}$ is positive if $y_{h}^{i}-a>k$. Likewise the right-hand side of equation 16 is monotonically decreasing in $\phi_{h}^{i *}$ and equal to zero if $\phi_{h}^{i *}$ is large. Therefore, there exists a unique equilibrium value of $\phi_{h}^{i *}$ for each $y_{h}^{i}$.

Below we will look at optimal policy. First we look at general training programmes, which historically were well established before the more targeted training programmes were introduced with the adaptation of active labour market policy. This happened over the 1990s in many advanced countries and is widespread today. Inspired thereby, we will after having considered optimal general training subsidies allow the government to condition 
the training subsidy on individual unemployment duration/risks, which is what most active programmes do.

\section{Optimal policy with a general training subsidy}

In this section, we characterize the equilibrium of the model allowing the government a general training subsidy in addition to its passive subsidy (the UI benefits). The problem is solved sequentially. We use the competitive equilibrium allocation of jobs and skills derived above given a set of government transfers. We can then solve for the optimal government transfers while taking the decentralized (optimal) decision rules for jobs and human capital as given.

The government executes the transfers $a, g$ and seeks to maximize the social welfare function

$$
Y=\max _{a, g} \gamma\left(\eta W_{h}^{A}+(1-\eta) W_{h^{\prime}}^{D}\right)+(1-\gamma) \min \left\{W_{h}^{A}, W_{h^{\prime}}^{D}\right\}
$$

such that (i) the government budget is balanced with taxes satisfying

$$
t=\eta\left(a u_{A}+h g\right)+(1-\eta)\left(a u_{D}+h^{\prime} g\right)<S_{A}, S_{D},
$$

where $h$ and $h^{\prime}$ indicate the respective human capital choices of advantaged and disadvantaged workers, (ii) a participation constraint (PC) that all workers prefer participation to benefits (i.e., no voluntary unemployed)

$$
W_{h}^{A}, W_{h^{\prime}}^{D} \geq a
$$


and (iii) the determination of $W_{h}^{A}$ and $W_{h^{\prime}}^{D}$ is given by the equilibrium outcome of the decentralized economy, which is described in section 2.2.

The solution to the government's problem yields the following propositions about optimal labour market policy. Suppose that the government is only interested in wealth maximization, that is $\gamma=1$. In this case, we have the following result.

Proposition 2 If social welfare is determined solely by aggregate wealth $(\gamma=1)$, optimal government is laissez faire.

Proof. Competitive search equilibrium ensures that any subsidy to one group of workers increases their output plus the subsidy an amount less than the cost of the subsidy.

If market tightness and human capital decisions are constrained efficient given the search frictions, a wealth maximizing government never gives subsidies that would distort these optimal decisions. Subsidies are only possible if the government evaluates a unit of income spent by a disadvantaged worker differently than a unit of income spent by an advantaged worker, that is, if $\gamma<1$. Still, a training subsidy that leads to the adoption of training by both advantaged and disadvantaged workers is not optimal. This is shown by the following proposition.

Proposition 3 Assume $\gamma<1$. A rational government never subsidizes the training of both advantaged and disadvantaged workers. 
Proof. If all agents adopt training, the cost of the subsidy is completely born by each group. Therefore, competitive search ensures that the optimal subsidy is zero for both groups of workers.

The direct implication of proposition 2 and 3 is that an optimal training subsidy must always exclude some workers, and it needs to be the advantaged workers that do not get subsidized training as the governments equity concern is the only possible motive for considering training. As we assume that the government cannot condition transfers on a particular workers type, the government will have to relay on self selection.

Suppose that the government seeks to direct the training subsidy to the disadvantaged workers. This objective is met if the following two incentive compatibility constraints (ICC) are obeyed: $W_{1}^{D} \geq W_{0}^{D}$ and $W_{0}^{A} \geq W_{1}^{A}$. That is, the disadvantaged workers take up subsidized training while the advantaged workers do not. More explicit, the constraints are,

$$
\begin{aligned}
G_{1}^{D}-\left(c_{D}-g\right) & \geq G_{0}^{D} \\
G_{0}^{A} & \geq G_{1}^{A}-\left(c_{A}-g\right) .
\end{aligned}
$$

The second incentive compatibility constraint implies that the maximum active subsidy to disadvantaged workers is given by

$$
g_{\max }=c_{A}-\left(G_{1}^{A}-G_{0}^{A}\right) .
$$

The behavior of $g_{\max }$ is closely related to the amount spent on passive subsidies as stated by the following proposition 
Proposition 4 The maximum incentive compatible training subsidy for disadvantaged workers, $g_{\max }$, increases as the passive subsidy, a, increases.

Proof. Comparative statics on equation (15) give $\partial\left(G_{1}^{A}-G_{0}^{A}\right) / \partial a<0$

The second ICC defines the minimum subsidy required to make disadvantaged workers train,

$$
g_{\min }=c_{D}-\left(G_{1}^{D}-G_{0}^{D}\right)
$$

Note that a government will subsidize a training programme only if

$$
g_{\min } \leq g_{\max }
$$

This inequality is satisfied only if the marginal increase in labour productivity is greater for disadvantaged workers than advantaged workers.

The preceding results concerning optimal government policy apply to any arbitrary social welfare function in our model. However, in order to derive an exact solution for optimal activation policy, it is convenient to assume (i) the social welfare function is given by equation (7) and (ii) disadvantaged workers are a relatively small fraction of the population. In this case

Proposition 5 If the government assigns a weight to equity $(\gamma<1)$ and disadvantaged workers are a sufficiently small part of the population ( $\eta$ is close to one), then the constraint optimal training subsidy is $g_{\max }$.

Proof. If $\eta$ is large, any training subsidy given by the government that does not lead to training by advantaged workers has virtually no effect on 
the level of taxation. In this case, the training subsidy can be treated purely as a reduction in training costs for the disadvantaged. This subsidy raises social welfare by an amount bounded away from zero if $\gamma<1$ with the welfare change of advantaged workers going to zero as $\eta$ approaching unity.

If disadvantaged workers are a large portion of the population, the optimal training subsidy is not necessarily $g_{\max }$. In this case, the result that the efficiency losses of training are small is not strictly valid. For example, if disadvantaged make up the entire population, proposition 3 establishes that the optimal general training subsidy is zero.

With a heterogenous population there is a case for a policy subsidizing training but it is haltered by the fact that the government cannot discriminated between advantaged and disadvantaged. Although it is possible for the government to sort workers by incentive compatible self-selection schemes, this is still not providing a strong case for a training subsidy. Passive transfers are still the most efficient way of reducing income inequality in this case as we will illustrate below.

Here we will also show that the picture changes dramatically if the government can use an extra piece of information like, for instance, the individual workers unemployment risk. Then all of a sudden, training subsidies become an efficient tool in providing equity. As the disadvantaged workers face higher unemployment risk and thus are more likely to experience long-term unemployment, all the information the government needs for implementa- 
tion is the duration of any unemployed workers current unemployment spell and then condition the training subsidies on the spell length.

There is, however, a complication to the use of unemployment experience as a screening criteria. Under such a policy it becomes an issue for the advantaged workers to try mimicking the disadvantaged workers in order to get subsidized training. When the training subsidy is offered unconditional this is of course not an issue.

The government needs to make sure that advantaged workers do not prefer subsidized training and long unemployment spells rather than no training subsidy and short unemployment spells. The government does not need to be concerned about the incentives of the disadvantaged workers as they simply cannot get re-employed fast enough to mimic the advantaged workers and neither would they gain anything from conducting such a behaviour.

\section{Targeted policy}

By its nature UI benefits are targeted to the unemployed. The type of active programmes that many countries have implemented are also directed at workers that are unemployed; in particular, at the long-term unemployed workers. In this section we illustrate the difference between a general subsidy and a subsidy targeted at the high risk workers in terms of their ability in order to provide equity efficiently. The advantage of targeted active policy lies in the way its complements passive policy. This complementarity is much weaker for a general education subsidy. 


\subsection{Unemployment as a screening device: active unemploy- ment programmes}

When we set up the incentive compatibility constraints (ICC) above we did not worry about workers not signalling their true type to the government. This we need to do here for the advantaged workers (the disadvantaged workers cannot mimic the advantaged one). Let $W_{h}^{A}\left(u^{\prime}\right)$ be the average income to an advantaged worker with training $h$ who has chosen unemployment $u^{\prime}$. Now the government needs to make sure that the advantaged workers do not want to be burdened with the unemployment rate of trained disadvantaged workers $u_{1}^{D}$ just to get the training subsidy, but rather prefer the unemployment rate of her own type $u_{0}^{A}$, that is, $W_{0}^{A}\left(u_{0}^{A}\right) \geq W_{1}^{A}\left(u_{1}^{D}\right)$. More explicitly, this ICC is $y_{0}^{A}\left(1-u_{0}^{A}\right)+a u_{0}^{A}-k v_{0}^{A} \geq y_{1}^{A}\left(1-u_{1}^{D}\right)+a u_{1}^{D}-k v_{1}^{D}-\left(c_{A}-g\right)$, where $v_{1}^{D}$ is the equilibrium vacancy in the submarket for trained disadvantaged workers. Recall that $y_{0}^{A}\left(1-u_{0}^{A}\right)+a u_{0}^{A}-k v_{0}^{A}=G_{0}^{A}\left(u_{0}^{A}\right)$. Thus, written in a form compatible with the ICC's of the previous section, we have,

$$
G_{0}^{A}\left(u_{0}^{A}\right) \geq G_{1}^{A}\left(u_{1}^{D}\right)-\left(c_{A}-g\right) .
$$

This constraint is more slack than the one needed in the previous section, which was $\left.W_{0}^{A}\left(u_{0}^{A}\right) \geq W_{1}^{A}\left(u_{1}^{A}\right)\right)$. This is so, because $W_{1}^{A}\left(u_{1}^{A}\right)>W_{1}^{A}\left(u_{1}^{D}\right)$, which follows from $u_{1}^{A}<u_{1}^{D}$ corresponding to $\phi_{1}^{A}>\phi_{1}^{D}$, as $\phi_{h}^{i}$ increases in productivity. Hence if advantaged workers should mimic disadvantaged workers, this corresponds to that they seem to have a lower productivity and thereby experience a higher unemployment rate as fewer vacancies are 
supplied.

Before we introduce the new ICC, $\left(\operatorname{ICC}\left(2^{\prime}\right)\right)$, into our model we will make an important simplification in order to facilitate the evaluating of a government training subsidies, which are targeted at workers who have a higher risk of unemployment. Suppose that $a$ is constant and that $g_{j}$ is given by 0 if individual $j$ is not in a training programme and $g$ if $j$ is being activated, that is, in a training programme. Note that this assumption will make the active transfers dependent on the equilibrium unemployment rate (of course $a$ is linearly dependent since it is only paid in the event of unemployment). We approximate the non-linear relationship between (i) the unemployment rate of a particular type of workers and (ii) the average amount of active training subsidies paid out to such workers by the following simple step-wise function

$$
g(u)=\left\{\begin{array}{llc}
g & \text { if } \quad u_{i} \geq u^{*} \\
0 & \text { if } & \text { otherwise }
\end{array}\right.
$$

This is only a crude representation of training subsidy that is conditioned on a sufficient unemployment duration. However, it should capture, to a close approximation, the essential non-linearity between benefit provision and the equilibrium unemployment rate of each group when benefits are determined by unemployment duration.

The per period income of a worker investing in human capital can be written as follows

$$
W_{h}^{i}=S_{h}^{i}-t=G_{h}^{i}-h\left(c_{i}-g\right)-t, \quad i \in\{A, D\}, h \in\{0,1\}
$$


where $G_{h}^{i}$ is the worker's labour market income as a function of their training decision, $g$ is the government's subsidy to training, $h\left(c_{i}-g\right)$ is the cost of training that is born by the worker, and $t$ is a lump sum tax determined by the government.

\subsection{Equilibrium with optimal targeted policy}

The model is unchanged except that the active transfer is paid only if the worker's type observes a sufficiently high unemployment rate. The equilibrium supply of jobs and human capital is approximated by the following static welfare optimization problem. The steady state welfare per worker per period of type $i \in\{A, D\}$ is given by

$$
G_{i}\left(u^{*}\right)=\max _{\substack{h \in\{0,1\} \\ \phi_{h}^{i} \geq 0}} \begin{cases}y_{h}^{i}\left(1-u_{h}^{i}\right)+a u_{h}^{i}-\left(c_{i}-g\right) h-k v_{h}^{i} & \text { if } u_{h}^{i} \geq u^{*} \\ y_{h}^{i}\left(1-u_{h}^{i}\right)+a u_{h}^{i}-c_{i} h-k v_{h}^{i} & \text { otherwise }\end{cases}
$$

where $\phi_{h}^{i}=v_{h}^{i} / s_{h}^{i}, u_{h}^{i}=e^{-\phi_{h}^{i}} s_{h}^{i}$ and $s_{h}^{i}=\delta /\left(\delta+(1-\delta)\left(1-e^{-\phi_{h}^{i}}\right)\right)$. Maximizing $G_{i}\left(u^{*}\right)$ gives

$$
\frac{y_{h}^{i}-a}{1-(1-\delta)\left(1-\lambda\left(\phi_{h}^{i *}\right)\right)} e^{-\phi_{h}^{i *}}=k
$$


which is the same as equation (15). The equilibrium training decision is given by

$$
h= \begin{cases}1 & \text { if } u_{1}^{i} \geq u^{*} \text { and } G_{i}\left(u^{*} \mid h=1\right)-G_{i}(h=0) \geq c_{i}-g, \\ 0 & \text { if } u_{1}^{i} \geq u^{*} \text { and } G_{i}\left(u^{*} \mid h=1\right)-G_{i}(h=0)<c_{i}-g, \\ 1 & \text { if } u_{1}^{i}<u^{*} \text { and } G_{i}(h=1)-G_{i}(h=0) \geq c_{i}, \\ 0 & \text { if } u_{1}^{i}<u^{*} \text { and } G_{i}(h=1)-G_{i}(h=0)<c_{i} .\end{cases}
$$

Suppose that the government can execute transfers $a, g$. The government seeks to maximize the social welfare function

$$
Y^{\prime}=\max _{a, g, u^{*}} \gamma\left(\eta W_{A}+(1-\eta) W_{D}\right)+(1-\gamma) \min \left\{W_{A}, W_{D}\right\}
$$

such that

$$
t \equiv \eta\left(a u_{A}+h g\right)+(1-\eta)\left(a u_{D}+h^{\prime} g\right) \leq S_{A}, S_{D}
$$

is the government's budget constraint. The constraints on this maximization problem are the fact that $a, g$ determine $u_{A}, u_{D}, h, h^{\prime}$ by the equilibrium supply of jobs and human capital in the previous subsection.

Welfare is always higher than in the basic model without targeted training, because activation gives the government an extra instrument to solve the incentive compatibility problem. In particular, the following policy menu is better.

1. For each value of the passive subsidy, $a$, compute the equilibrium unemployment rate, $u^{*}$, of trained disadvantaged workers.

2. Calculate the payoffs of (i) untrained advantaged workers and (ii) unsubsidized trained advantaged workers when the unemployment rate 
of advantaged workers is $u^{*}$.

3. Set the subsidy of disadvantaged workers equal to the difference of (i) and (ii) in 2 .

The reason this scheme outperforms the scheme in the previous section is that the payoff of the unsubsidized constrained trained advantaged workers in 2 is lower than the payoff of unconstrained trained advantaged workers. In particular, for a given passive subsidy, the incentive compatibility constraint of active subsidies is weakened if they are targeted to the long term unemployed. The fact that advantaged workers must mimic the unemployment rate of disadvantaged workers (experience a large duration in unemployment), implies that a larger active subsidy can be paid to disadvantaged workers. Therefore, an incentive compatible training subsidy can be paid to disadvantaged workers even if the training yields significant productivity benefits for advantaged workers, who will otherwise go untrained if training is not subsidized.

The effect of these targeted policies on the relationship between active and passive subsidies is also changed. In the diagram we observe that at low values of the passive subsidy there is only a small gap (the line from point a to b) between the unemployment rates of trained advantaged and disadvantaged workers. In this case, there is only a small additional cost to advantaged workers of accepting the unemployment rate of disadvantaged workers (which is suboptimal from the point of view of advantaged workers) 


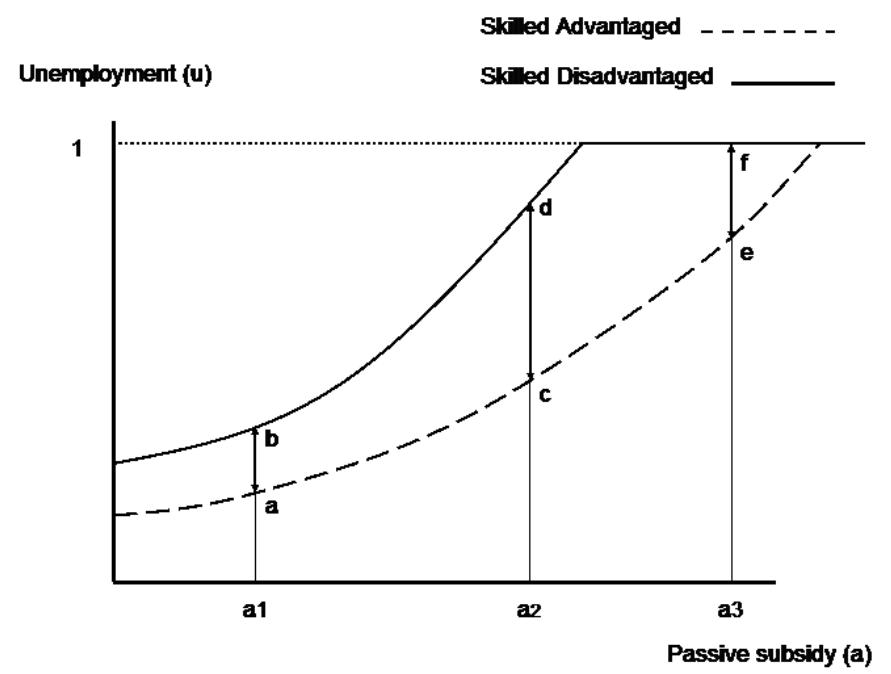

Figure 3: Unemployment and the passive subsidy

in order to gain the training subsidy. In the diagram, we see that the gap between the two unemployment rates widens as the passive subsidy increases. Therefore, the cost of accepting the unemployment rate of disadvantaged workers is larger. Thus even larger active subsidies can be delivered to disadvantaged workers without violating the incentive compatibility constraint that advantaged workers do not accept the training subsidy.

In the next section we illustrate the difference between combining a traditional general UI benefit scheme with a targeted training subsidy and a general training subsidy by performing some quantitative analysis. The results just presented concludes that targeted training reduces the trade-off between obtaining efficiency and reducing inequality by raising opportunities for disadvantaged workers. This result is confirmed by simulations in 
the next section.

\section{Quantitative Analysis}

This section presents data on the pattern on spending in OECD countries. We then do two simulations of our model. First, we simulate the model with training subsidies that are not conditioned on unemployment. Then the model is simulated with training subsidies that are conditioned on unemployment.

We observe that there is a positive correlation between how much money is spent on passive programmes and how much money is spent on active programmes. Furthermore, high spending countries seem to operate on a more favorable equity-efficiency trade off than the other countries. We see this by comparing Figure 2, which pictures the equity-efficiency trade-off for some selected OECD countries, to Figure 1. (See Figure 1 and 2 in the Introduction). This subsection evaluates the implications of the model numerically. We simulate the model in order to determine whether the model can replicate the observed variations in economic efficiency, equity and spending on active and passive policies. The baseline model assumes parameters that give labour market flows and income measures for low income groups in the economy which usually are characterised by very high unemployment rates.

Considering as a baseline the case where the economy is completely laissez faire, we then see how this economy behaves as a greater concern for equity is introduced. 


\subsection{Numerical Simulation I}

The following is a simulation of the model without time varying subsidies to training. 
Table 1: Simulations for the non-targeted case.

\begin{tabular}{|l|l|l|l|l|}
\hline & & $\gamma=0.25$ & $\gamma=0.5$ & $\gamma=0.75$ \\
\hline & $a=0$ & $a=0.337$ & $a=0.224$ & $a=0.112$ \\
& $g=0$ & $g=0.0802$ & $g=0.0775$ & $g=0.0751$ \\
\hline$u_{1}^{D}$ & 0.2080 & 0.1850 & 0.1667 & 0.1523 \\
\hline$u_{0}^{A}$ & 0.1255 & 0.1585 & 0.1454 & 0.1346 \\
\hline$u$ & 0.1296 & 0.1598 & 0.1465 & 0.1355 \\
\hline$S_{D}$ & 0.3424 & 0.4912 & 0.4898 & 0.4874 \\
\hline$S_{A}$ & 0.8658 & 0.8553 & 0.8593 & 0.8614 \\
\hline Efficiency loss, pct. & - & 15.74 & 16.19 & 16.41 \\
\hline Equality gain, pct. & - & 30.44 & 29.40 & 28.54 \\
\hline Gain D, pct. & - & 43.47 & 43.06 & 42.36 \\
\hline Loss A, pct. & - & 1.21 & 0.75 & 0.51 \\
\hline
\end{tabular}

The parameters of the model are:

\begin{tabular}{|l|l|l|l|l|l|l|l|l|l|}
\hline Parameter & $y_{D}^{1}$ & $y_{D}^{0}$ & $y_{A}^{1}$ & $y_{A}^{0}$ & $\delta$ & $c_{D}$ & $c_{A}$ & $\eta$ & $k$ \\
\hline Value & 1.27 & 0.82 & 1.70 & 1.44 & 0.3 & 0.3 & 0.3 & 0.95 & 0.9 \\
\hline
\end{tabular}

If the subsidy to training is general (i.e. not conditioned on unemployment), then subsidies to active and passive labour market programmes are not closely related, spending on the active subsidies is small, and there exists a large trade-off between equity and efficiency.

\section{$5.2 \quad$ Numerical Simulation II}

The following is a simulation of the model in which unemployment rates act as a screening device for the delivery of active benefits. Hence, only workers 
facing high unemployment rates receive active benefits. That is, we consider simulations for the targeted case. Table 2 shows the results. 
Table 2: Simulations for the targeted case.

\begin{tabular}{|l|l|l|l|l|}
\hline & & $\gamma=0.25$ & $\gamma=0.5$ & $\gamma=0.75$ \\
\hline & $a=0$ & $a=0.595$ & $a=0.330$ & $a=0.155$ \\
& $g=0$ & $g=0.1125$ & $g=0.0927$ & $g=0.0853$ \\
\hline$u_{1}^{D}$ & 0.2080 & 0.2516 & 0.184 & 0.1574 \\
\hline$u_{0}^{A}$ & 0.1255 & 0.2017 & 0.1576 & 0.1385 \\
\hline$u$ & 0.1296 & 0.2042 & 0.1589 & 0.1395 \\
\hline$S_{D}$ & 0.3424 & 0.5095 & 0.503 & 0.4973 \\
\hline$S_{A}$ & 0.8658 & 0.8320 & 0.8550 & 0.8603 \\
\hline Efficiency loss, pct. & - & 13.21 & 15.77 & 16.35 \\
\hline Equality gain, pct. & - & 38.39 & 32.80 & 30.64 \\
\hline Gain D, pct. & - & 48.81 & 46.98 & 45.25 \\
\hline Loss A, pct. & - & 3.91 & 1.25 & 0.63 \\
\hline
\end{tabular}

The parameters of the model are the same as the previous subsection.

If the training subsidy is targeted, then subsidies to active and passive labour market programmes are more strongly positively related, spending on active subsidies is larger, and there exists a smaller trade-off between equity and efficiency.

Figure 4 shows a graphic representation of the difference in-between the targeted and the non-targeted case. The upper graph represents welfare maximising values of the passive subsidy $a$ and the active subsidy $g$ as $\gamma$ varies when the training subsidy is targeted on the group of workers experiencing the highest rate of unemployment. The lower graph represents welfare maximising values of the passive subsidy $a$ and the active subsidy $g$ as $\gamma$ varies when the training subsidy is general. The parameter $\gamma$, rep- 
resenting the weight put on the Benthamite sum of utilities social welfare function, decreases as we move from left to right in the figure. Hence, as confirmed in the two tables, a lower $\gamma$, that is a relatively higher weight on equality leads to higher welfare maximising values of $a$ and $g$. We observe that higher values of both active and passive subsidies are reached for given $\gamma$ in the targeted case. Furthermore, the lower $\gamma$ is, the larger is the increase in the welfare maximising value of $g$ in the targeted case, but not in the case of a general subsidy.

These exercises have illustrated that active and passive subsidies can be strategic complements. The strength of this complementarity is greatly increased if the active subsidy is targeted. This occurs because higher passive benefits tends to raise the unemployment rate of disadvantaged workers which in turn weakens the incentive compatibility constraint on the active subsidy. And, in contrast to a general subsidy, a targeted active subsidy can be delivered optimally to disadvantaged workers even if the marginal gain in productivity (from training) is higher for advantaged workers. Finally, disadvantaged workers must experience a larger gain in productivity if their training is to be subsidized using a non targeted active subsidy.

\section{Conclusions}

The massive and persistent emphasis put on activation and training of unemployed individuals in developed countries in general and in big-welfare-state countries in particular is a puzzle, because it has been difficult to identify 


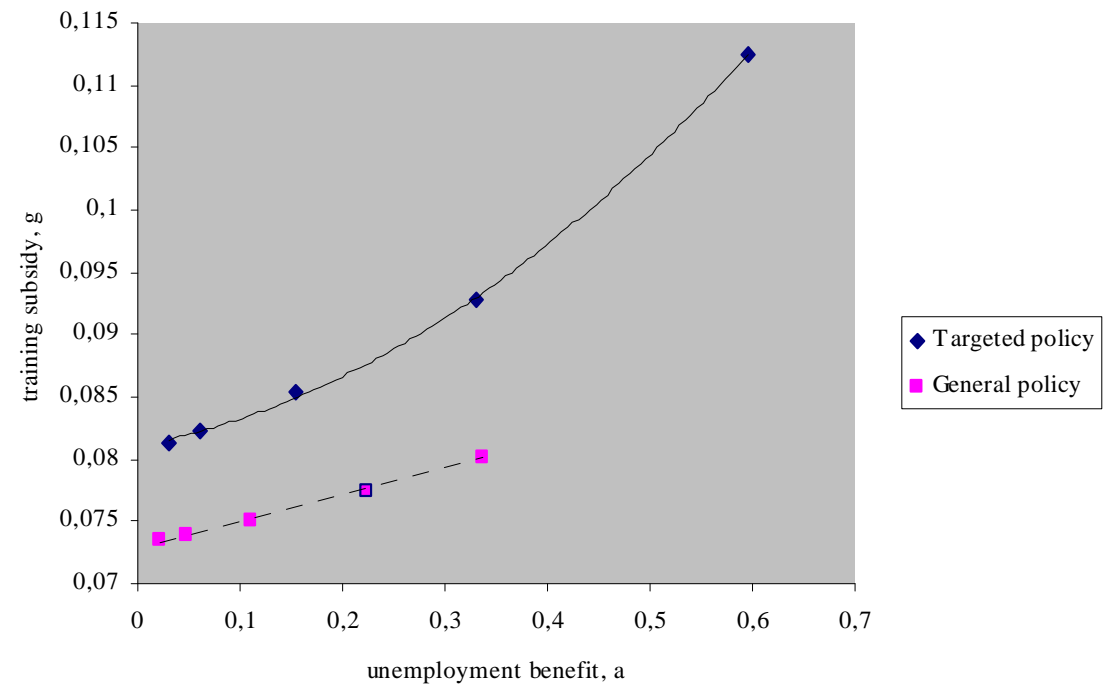

Figure 4: Welfare maximising values of $a$ and $g$ as the weight on equity increases, that is $\gamma$ decreases from 0.95 to 0.25 going from left to right.

positive effects - individual as well as macro-level effects - from the often huge spending on these programmes. This is surveyed by Martin (2000) Heckman, Lalonde, Smith

1999) and OECD (2003). So either politics are irrational or the profession has not been looking for effects in the right places. For instance, even if there are no effects at the mean for any of the programmes, there could be an effect at the macro level - e.g., less inequality - if it is the more disadvantaged workers who gain productivity from the programmes. This is conceivable as Martin (2000), Heckman, Lalonde, and Smith (1999) and OECD (2004) also conclude that some programmes have very significant effects for some groups of individuals. I OECD (2003) it is also suggested that activation 
policies have reduced poverty rates in some European countries.

Suppose income equality is a main objective for some countries along side with high average income. Could it then be that active programmes are favored by some countries because such programmes reduce inequality efficiently when used together with traditional passive programmes like UI benefits? This is the question that we have been discussing in this paper and the answer is in the affirmative. If income equality is a sufficiently strong objective to a government then it might well be rational to implement active training programmes for the long term unemployed together with passive benefit programmes like UI. This combination is far more effective that the combination of UI benefits and a general education subsidy. At the principal level, this could vindicate high spending on activation by countries with strong taste for equity. Our results also suggests that high passive and active spending goes hand in hand. Both these phenomenon can be observed in the data for the OECD countries.

These results are developed in a model with heterogenous workers, human capital investment, and unemployment. The model is "pure" in the sense that 'laissez faire' is efficient: the privately chosen level of training is efficient and even though disadvantaged workers of low skills are the more unemployed ones, unemployment is efficient and reflects search and matching frictions. There are no externalities to justify training subsidies. We have also deliberately disregarded the traditional insurance aspect of passive policies by letting agents be risk neutral in our model. So it is not the 
usual missing insurance market that implies government spending on UI in optimum. The redistributive functioning of UI in this model with heterogenous unemployment risk is enough to have passive transfers to unemployed entering the optimal policy packaged (of a government that maximizes a social welfare function that puts weight on both equity and income efficiency).

Furthermore, not only can we explain the joint use of passive and active subsidies, the model also shed light on the big variation in the labour market policies of OECD countries. Our results suggest that much of the variation in policy can be explained by different social objectives rather than by inefficient policy or differences in technology and human capital.

The analysis of this paper can be improved in two directions. First, the empirical assessment of the theory is only suggestive. An involved empirical study is needed to isolate the specific causes of policy variation across OECD countries. Second, the theory of the model could also be extended to incorporate a more detailed description of active labour market programmes. For example, different elements of active programmes, including different subsidies for training employed and unemployed workers, could be studied. We leave these improvements for further research.

\section{References}

[1] Blundell, R. (2004), Labour Market Policy and Welfare reform: Meeting Distribution and Efficiency Objectives, De Economist, June 2004, v. 152, no. 2, pp. 233-250. 
[2] European Commission (2004), Employment in Europe 2004 - Recent Trends and Prospects, European Commission, Employment and social affairs.

[3] Fredriksson, Peter and Bertil Holmlund (2003), Improving incentives in unemployment insurance: A review of recent research, IFAU Working Paper 2003:5.

[4] Heckman, James J., Robert J. Lalonde, and Jeffrey A. Smith (1999), The Economics and Econometrics of Active Labor Market programmes, Handbook of Labor Economics, Vol 3A, Ed. A. Ashenfelter and D. Card, Elsevier Science, Amsterdam, pp. 1865-2097.

[5] Julien, Benoit; Kennes, John; King, Ian; Bidding for Labour, Review of Economic Dynamics, October 2000, v. 3, iss. 4, pp. 619-49.

[6] Martin, J.P. (2000), What Works Among Active Labour Market Policies: Evidence from OECD Countries' Experiences, OECD Economic Studies, 2000,no. 30, pp. 79-113

[7] OECD (2003), Benefits and Employment, Friend or Foe? Interactions Between Passive and Active Social Programmes, OECD Employment Outlook, 2003.

[8] OECD (2004), Improving Skills for More and Better Jobs: Does Training make a Difference?, OECD Employment Outlook, 2004. 
[9] Pavoni, Nicola and Giovanni L. Violante (2004), Optimal Welfare-toWork programmes, manuscript UCL/IFS and NYU.

[10] Shimer, Robert, 2001, The Assignment of Workers to Jobs In an Economy with Coordination Frictions, October 2001, pp. 35, National Bureau of Economic Research Working Paper: 8501. 


\section{Appendix}

\subsection{Spending on Active and Passive Policy}

Active and passive Labour market policy as percentages of GDP for selected OECD countries for a time period is illustrated in Figure 5. An apparent complementary pattern, found in Figure 1, is also found following a particular country over time. The lines in Figure 5 are simple OLS predictions country by country.

For Denmark and the Netherlands, active and passive policy seems to be substitutes, nevertheless. The following figures show that in these cases major reforms are visible as structural shifts. In Denmark in 1994, there was a general shift towards mandatory activation and in general more emphasis was put on active labour market policy relatively to passive policy. This could explain the shift to the right that we see in Figure 6. In the Netherlands there was a major restructuring of the benefit system in 1987. The replacement ratios were lowered from 80 to $70 \%$ and eligibility rules were tightened. Again in 1996 the benefit sanction system was further toughened and in 1998 the Netherlands Job-seekers Employment ACT was introduced. During the more stable years in between we do observe a complementary pattern between active and passive policy (see Figure 7) although it is week. 


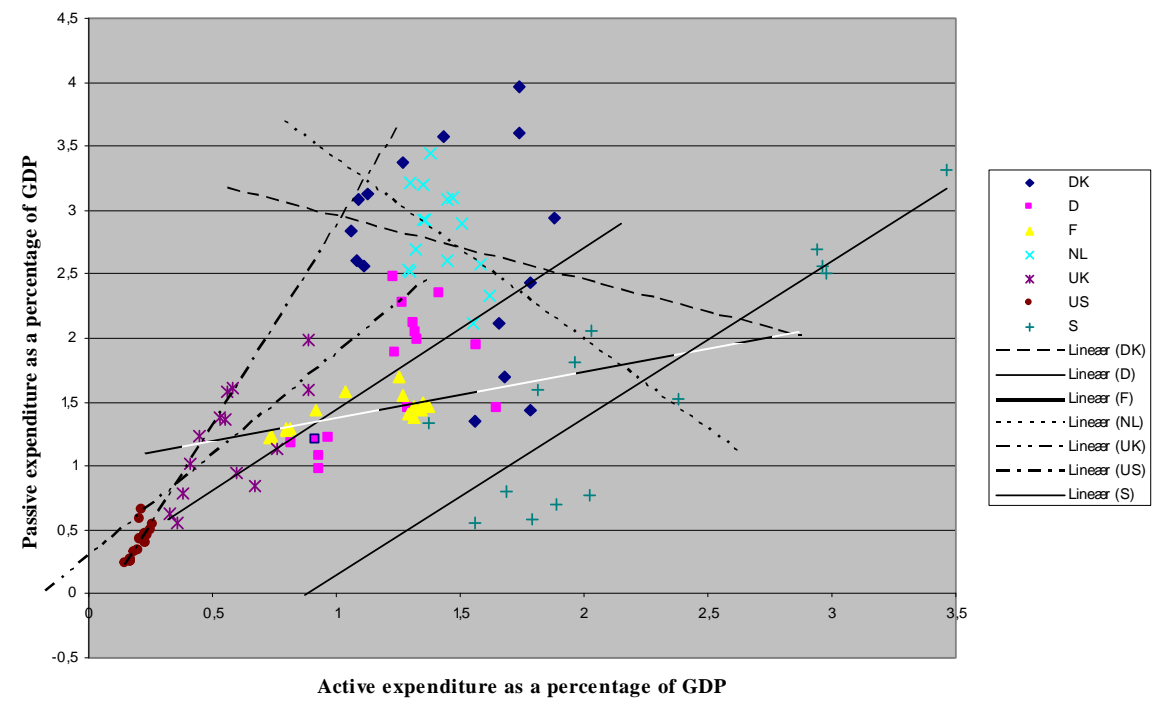

Figure 5: Active and passive expenditures as a percentage of GDP, selected OECD countries, 1986-2000

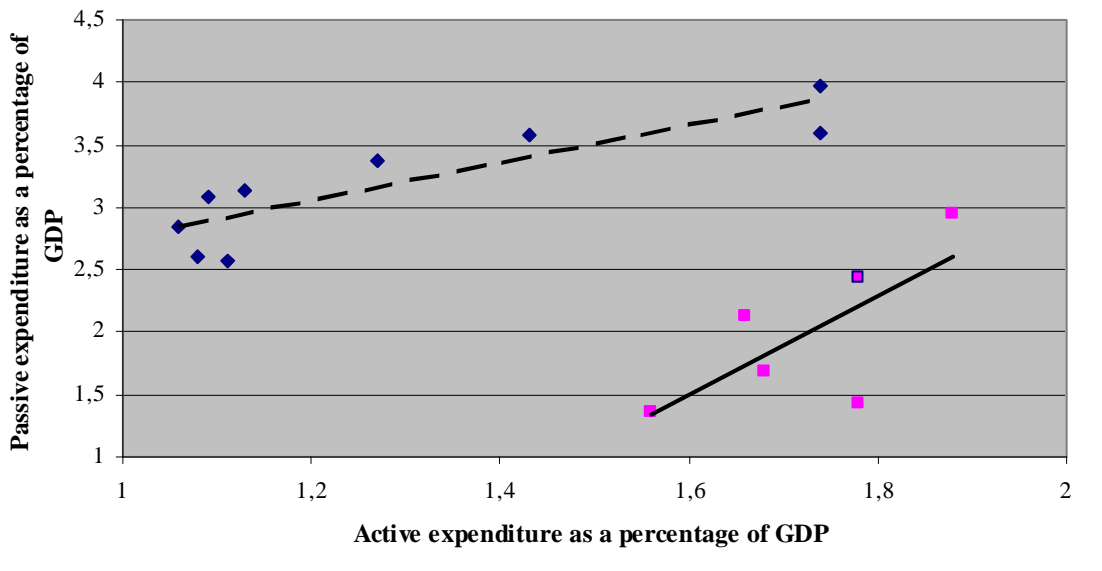

Figure 6: Active and passive expenditures as a percentage of GDP, Denmark, 1986-2000 


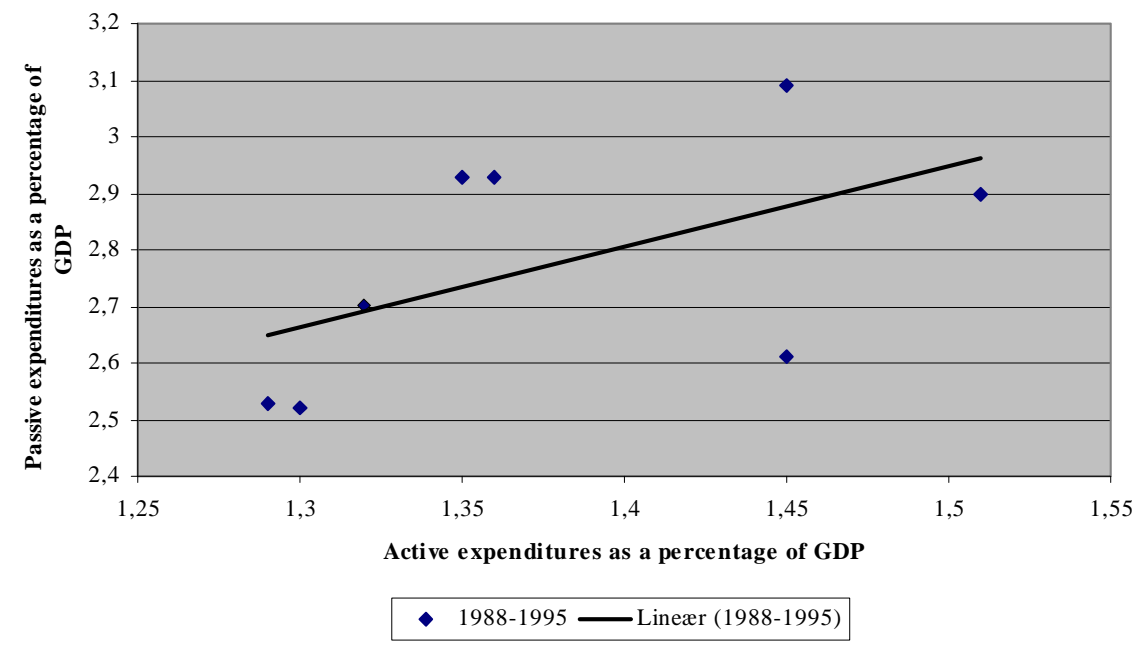

Figure 7: Active and passive expenditures as a percentage of GDP, the Netherlands, 1988-1995

\section{Solution Equivalence}

This appendix shows that the decentralized economy is equivalent to the solution of a simple static maximization problem if the discount factor approaches unity. (1) The decentralized asset equations are given by

$$
\begin{gathered}
\Lambda=\frac{y+\beta \delta(V+\Pi)}{1-\beta(1-\delta)} \\
\Pi=0 \\
V=V(u)+\left(1-e^{-\phi}-\phi e^{-\phi}\right)(\Lambda-V(u)) \\
\Pi=-k+e^{-\phi}(\Lambda-V(u)), \\
V(u)=a+\beta V
\end{gathered}
$$


These equations for $\Lambda, V, V(u), \Pi$ and $\phi$ can rewritten to get a single expression for $\phi$.

$$
k=y e^{-\phi}+k(1-\delta) \beta\left(e^{-\phi}+\phi e^{-\phi}\right)
$$

and that in the limit as $\beta$ approaches 1 we get

$$
k=y e^{-\phi}+k(1-\delta)\left(e^{-\phi}+\phi e^{-\phi}\right)
$$

(2) Now consider the simple static problem of maximizing steady state output less recruiting costs. In this case

$$
W=\max _{\phi} y(1-u)+a u-k v
$$

such that

$$
\begin{gathered}
\phi=v / s \\
s=\frac{\delta}{\delta+(1-\delta)\left(1-e^{-\phi}\right)} \\
u=s\left(1-e^{-\phi}\right)
\end{gathered}
$$

The solution to this problem is the same as A1. 